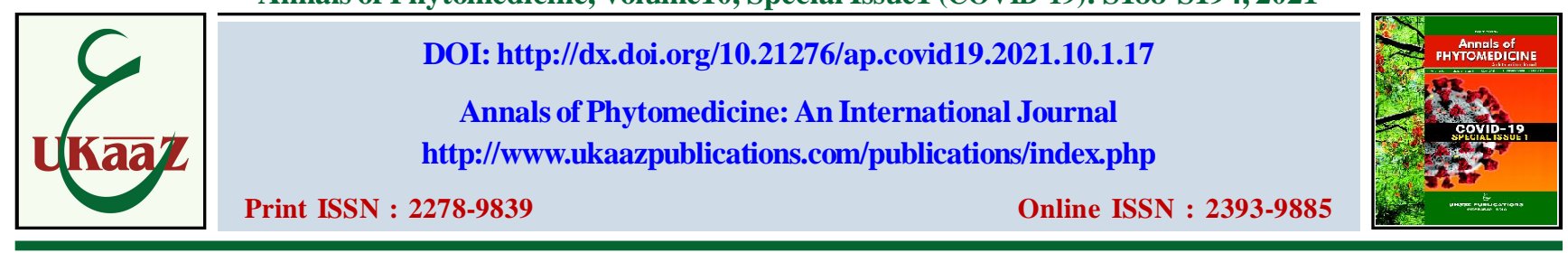

\title{
Prevalence of coinfections with ESKAPE pathogens in COVID-19 patients: A review
}

\author{
Muhammad Musthafa Poyil* \\ Department of Basic Medical Sciences, College of Medicine, Prince Sattam bin Abdulaziz University, Al-Kharj, 11942, Saudi Arabia
}

\begin{tabular}{l} 
Article Info \\
\hline Article history \\
Received 10 May 2021 \\
Revised 27 June 2021 \\
Accepted 28 June 2021 \\
Published Online 30 June 2021
\end{tabular}

\section{Keywords}

COVID-19

Bacterial coinfections

ESKAPE pathogens

Antimicrobial resistance
Multidrug resistant bacteria

\begin{abstract}
The emergence and worldwide spread of the COVID-19 pandemic, which is being caused by a type of coronavirus named as SARS-CoV-2, has unprecedentedly challenged the healthcare system across the globe. To add to the catastrophe brought about by this viral infectious disease, coinfections by other microbial agents including bacteria and fungi further deteriorate the health of COVID-19 patients by developing multiple dreaded diseases, resulting in extended morbidity and high rate of mortality all over the world. There are a number of multidrug resistant bacterial species which cause these coinfections both in community environments and hospital set ups including in the ICUs. Among the multidrug resistant bacterial species that are responsible for tens of thousands of deaths per annum around the globe, the infectious diseases society of America (IDSA) has shortlisted and the world health organization (WHO) has recognized the importance of the most dangerous 'bad bugs' dubbed as 'ESKAPE' pathogens and the members are Enterococcus faecium (E), Staphylococcus aureus (S), Klebsiella pneumoniae (K), Acinetobacter baumannii (A), Pseudomonas aeruginosa $(\mathrm{P})$ and Enterobacter species and Escherichia coli (E). Each one of the above mentioned bacterium has many MDR strains and complex antimicrobial resistance mechanisms. In this review, I try to find out the reported prevalence of these pathogens in COVID-19 patients admitted to various healthcare facilities across the world.
\end{abstract}

\section{Introduction}

It was just the beginning of an unprecedented pandemic catastrophe when a number of people were presented with a kind of atypical pneumonia in and around Wuhan city of Hubei Province in China in December 2019 (Ansari et al., 2021). As the spread went uncontrolled, the scientists began the detailed investigations and confirmed the cases as severe acute respiratory syndrome (SARS), caused by a kind of coronavirus, which later termed as SARS-CoV-2 by the coronavirus study group (CSG) of the International Committee on Taxonomy of Viruses (ICTV) (Zhu et al., 2020). As of May 23, 2021, there are 166,346,635 confirmed COVID-19 cases including $3,449,117$ deaths worldwide (https://COVID-19. who.int/updated on 22/05/2021). The causative virus is an enveloped, Coronaviridae family member with a single stranded RNA (Sola et al., 2015) and the disease caused by it was later officially named as COVID-19 on 11 February 2020 (Ansari et al., 2021; Rothe et al., 2021) and on March 11 in the same year, the WHO declared the COVID-19 as a pandemic (Ghebreyesus, 2020).

COVID-19 is a systemic infection which affect a wide variety of cells and tissues (Vazzana et al., 2021). The disease becomes more fatal when it gets complicated with bacterial and/or fungal coinfections or super infections and secondary infections especially with multidrug resistant (MDR) or antimicrobial resistant (AMR) resistant pathogenic strains, which of them were detected in 50\% of COVID-19 deaths (Rossato et al., 2020; Cole et al., 2021; Rawson et al., 2021; Lai et al., 2021; Patel et al., 2021; Knight et al., 2021).

Corresponding author: Mr. Muhammad Musthafa Poyil Department of Basic Medical Sciences, College of Medicine, Prince Sattam Bin Abdulaziz University, Al-Kharj, 11942, Saudi Arabia E-mail: pmusthu@gmail.com

Tel.: +96-6565634412

Copyright (c) 2021 Ukaaz Publications. All rights reserved.

Email: ukaaz@yahoo.com; Website: www.ukaazpublications.com
Various AMR and MDR strains of different bacterial pathogens are responsible for around 700,000 annual deaths across the globe and is predicted to reach 10 million mortalities per year by 2050 (Fattorini et al., 2020; Rossato et al., 2020; Chen et al., 2020; Mazdeyasna et al., 2020; Rawson et al., 2020; Mirzaei et al., 2020; Rusic et al., 2021; Ansari et al., 2021; Rawson et al., 2021; Lai et al., 2021; Patel et al., 2021; Mayoral et al., 2021; Pelfrene et al., 2021; Majumder et al., 2021; Prasetyoputri 2021). Out of these 'bad bugs', in 2007, the Infectious Diseases Society of America (IDSA) had selected the five most dangerous AMR bacterial species which show cunning "escape" from antimicrobial agents through a variety of complicated resistance mechanisms, thereby causing higher mortality and more healthcare expenses, and are dubbed as "ESKAPE" pathogens (Musthafa et al., 2020; Majumder et al., 2021). They are Enterococcus faecium (E), Staphylococcus aureus (S), Klebsiella pneumoniae (K), Acinetobacter baumannii (A), Pseudomonas aeruginosa $(\mathrm{P})$ and Enterobacter species and Escherichia coli (E) and the world health organization (WHO) has listed them in the Priority Pathogens List ('PPL'-published in 2017) of 12 bacterial pathogens against which potential antimicrobial agents are urgently required (Ramsamy et al., 2018; Mulani et al., 2019; Ansari et al., 2021). The major purpose of IDSA's antimicrobial stewardship (AMS) program, started in 2007 was to control this 'ESKAPE' menace (Majumder et al., 2021). The coinfections with the antimicrobial resistant ESKAPE members often result in lifethreatening complications along with the COVID-19. This article reviews the catastrophe reported by the coinfections with each one of the members of the ESKAPE pathogens.

\section{Bacterial coinfections in COVID-19 in general}

The unprecedented health crisis worldwide, due to the ongoing COVID-19 has multiplied with the concerns brought by the AMR bacterial coinfections (Rawson et al., 2021). An ever increased 
prevalence of AMR infections have been reported with the COVID19 , ranging from common nosocomial infections to bacteremia, hospital-acquired pneumonia and ventilator-associated pneumonia (Garcia-Vidal et al., 2020; Rawson et al., 2021).

Different investigations found out COVID-19 bacterial coinfections at various levels, and the causative agents included MDR strains of high priority categories like vancomycin resistant Enterococci (VRE) including Enterococcus faecium, vancomycin-intermediate/resistant Staphylococcus aureus (VISA/VRSA), methicillin-resistant Staphylococcus aureus (MRSA), extended-spectrum beta-lactamase (ESBL) producing Klebsiella pneumoniae (ESBLKp), carbapenemresistant Acinetobacter baumannii (CRAB), ESBL producing Pseudomonas aeruginosa, carbapenem-resistant Enterobacteriaceae (CREB), ESBL producing Escherichia coli, carbapenemresistant NDM-producing Enterobacterales, clarithromycin-resistant Helicobacter pylori (CRHP), Enterobacter cloacae, fluoroquinolone resistant Campylobacter spp., Salmonella spp., cephalosporin and fluoroquinolone-resistant Neisseria gonorrhoeae, penicillinresistant Streptococcus pneumoniae (PRSP), ampicillin-resistant Haemophilus influenza, fluoroquinolone-resistant Shigella spp., Chlamydophila pneumoniae, Mycoplasma pneumoniae, Legionella pneumophila, Stenotrophomo nasmaltophilia, Mycobacterium tuberculosis, Serratia spp. including Serratia marcescens, Proteus spp., Mycoplasma species, etc., were the bacterial pathogens most often observed (Sharifipour et al., 2020; Contou et al., 2020; Lai et al., 2020; Yang et al., 2020; Chen et al., 2020; Ansari et al., 2021; Rawson et al., 2021; Lai et al., 2021).Studies on bacterial coinfections in COVID-19 patients reported by (Sharifipour et al., 2020; Rawson et al., 2021; Lai et al., 2021) have also brought about the presence of other pathogenic bacteria which are resistant to resistant to third-generation cephalosporins and amoxicillin/ clavulanate.

\section{Coinfections by ESKAPE pathogens in COVID-19 patients}

\subsection{Enterococcus faecium}

Enterococci are Gram positive, aerobic or facultative anaerobic, opportunistic pathogens frequently involved in healthcare associated infections (HAIs) or nosocomial infections and can cause severe infectious diseases especially among immunocompromised patients (Santajit and Nitaya Indrawattana, 2016; Said et al., 2020). Various studies have shown that this species is common in COVID19 patients. A retrospective study conducted by Rothe et al., (2021) in 140 COVID-19 patients at the German University hospital admitted between February and April 2020 showed blood infection with vancomycin-resistant Enterococcus faecium including two Van B phenotypic strain confirmed by molecular technique. In another study, Feldman and Anderson (2021) described about the isolation of Enterococcus faecium along with other bacterial pathogens from the blood and BAL samples. An observational cohort analysis at the University Hospital Clinic of Barcelona for COVID-19 patients during the period of 28 February to 22 April 2020 showed the presence of Enterococcus faecium in $14.2 \%$ of the COVID-19 patients at the time of admission and in $18.7 \%$ of patients as hospital acquired super-infective complications after being admitted (GarciaVidal et al., 2020).

Another retrospective analysis on 32 COVID-19 ICU patients admitted to the Monaldi Hospital, Naples, Italy in March and April 2020 revealed the prevalence of $13 \%$ of invasive MDR
Enterococci with presence of $9 \%$ of Enterococcus faecium (Karruli et al., 2020). These isolates were even resistant to higher concentration of aminoglycosides and the study found out that one of one strains of Enterococcus faecium was resistant to even ampicillin. Rawson et al. (2020) observes that, critically ill patients receiving treatment using invasive catheters are at a high risk of secondary infections with MDR bacterial strains including that of Enterococcus spp. Ukuhor et al. (2021) also reported COVID-19 coinfections with AMR strains of Enterococcus spp.

\subsection{Staphylococcus aureus}

Staphylococcus aureus is Gram positive, coccus shaped and is the most common member of skin microflora with about $30 \%$ of skin or noses of healthy people are colonized with this bacterium (Navidinia et al., 2016; Taylor and Unakal, 2020). Staphylococcus aureus has been known for its involvement in severe clinical coinfections in COVID-19 patients and the coinfection by hospital acquired strains are like methicillin-resistant Staphylococcus aureus (MRSA) are of a great threat (Punjabi et al., 2020).

A cohort of COVID-19 ICU patients at a referral hospital in Qom, Iran was studied for their coinfections and found that $10 \%$ of them were infected with MDR Staphylococcus aureus including MRSA (Sharifipouret al., 2020). Another retrospective investigation in France found out that $28 \%$ of severely ill COVID-19 patients had bacterial coinfection including with that by methicillin-sensitive Staphylococcus aureus (Contou et al., 2020). A study conducted by Kathrin Rothe et al. (2021), with the respiratory samples of on 140 COVID-19 inpatients at a German University hospital during February-May 2020 detected the presence of Staphylococcus aureus at $13 \%$ including MRSA. At a Spanish hospital, in a prospective study, $26 \%$ of 92 COVID-19 patients were shown early infections (at the time or within $48 \mathrm{~h}$ of admission to the ICU) and $46.7 \%$ with later infections with Staphylococcus aureus (Barrasa et al., 2020). The study by Contou et al. (2020) also found out that the $28 \%$ of ICU COVID-19 patients at a French hospital were having early infections and Staphylococcus aureus was one of the prominent members. Wolfe (2020) and colleagues reported that $55.8 \%$ of total bacterial co-pathogens isolated from COVID-19 patients were Staphylococcus aureus. Garcia-Vidal et al., (2020) in their report on coinfection and superinfection by bacterial pathogens in 989 COVID-19 inpatients at a hospital in Barcelona, Spain said that, $3 \%$ of the patients were having Staphylococcus aureus pneumonia with $44 \%$ of coagulase-negative Staphylococci as the most predominant in bloodstream infectious agent. Another retrospective study at Desio Hospital, Lombardy, Italy conducted on COVID-19 patients showed coinfections by Staphylococcus aureus at a level of 5\% (Intra et al., 2020). Other investigations like that of Mayoral et al. (2021) also underline the findings, reporting the presence of Staphylococcus aureus up to $15 \%$ in among isolate in COVID-19 ICU patients.

A report by Duployez et al. (2020) mentioned about the presence of panton-valentine leucocidin (PVL) secreting Staphylococcus aureus which caused a dangerous necrotizing pneumonia in a COVID-19 patients. The microbiological investigations on COVID19 patients hospitalized in New York identified the presence of Staphylococcus aureus in $44 \%$ of the patients (Sharifipour et al., 2020) and this finding was verified by Fattorini et al. (2020). An observational cohort analysis at the University Hospital Clinic of 
Barcelona, which was mentioned elsewhere in this article could also find out the presence of methicillin resistant Staphylococcus aureus which contributed $4 \%$ of total bacterial isolates from COVID19 ICU patients (Garcia-Vidal et al., 2020). Many clinical investigations across the world, like that of Rusic et al. (2021) have also pictured Staphylococcus aureus as the most prevalent cause for secondary bacterial infection in COVID-19 patients.

\subsection{Klebsiella pneumoniae}

Klebsiella pneumoniae is Gram negative, rod shaped, non-motile, bacteria that belongs to Entero bacteriaceae family (Ashurst and Dawson, 2021). Together with Escherichia coli, they pose a great health threat as they are prevalent globally in community areas and hospital environments (Pendleton et al., 2013). Investigation on COVID-19 patients in various healthcare facilities across the world have shown theat this bacterium has been playing a crucial role in extended morbidity and higher rate of mortalities. 11 samples out of 23 respiratory samples from the COVID-19 patients at the German University hospital, a study mentioned elsewhere in this review, could show the presence of Klebsiella spp. with one sample having Klebsiella pneumoniae (Rothe et al., 2021). Rawson et al. (2021) describes about a study at a Barcelona Hospital ICU for COVID-19 patients where pathogens including Klebsiella spp. were responsible for some clinical complications like bacteraemia, hospital-acquired pneumonia, ventilator-associated pneumonia, etc. Another study reported by Intra et al.(2020) at the COVID-19 ICU of Desio Hospital, Lombardy, Italy also confirmed the presence of $3 \%$ Klebsiella pneumoniae. In Wuhan, China, Li et al. (2020) reported that, $30.8 \%$ of the total isolates caused acquired secondary infections among COVID-19 patients were due to Klebsiellapneu moniae. Chen et al. (2020) conducted a retrospective study based at a COVID-19 care facility in Wuhan, on 99 cases in 2019 and reported that Klebsiella pneumoniae was one of the prominent members that caused bacterial coinfections. The A retrospective study among the ICU patients at the German University hospital during February - May 2020 by Kathrin Rothe et al., (2021), with the respiratory samples of on 140 COVID-19 inpatients revealed the presence of Klebsiella spp. in $7.9 \%$ of isolates.

The presence of Klebsiella pneumoniae in SARS-CoV-2 patients with bacterial coinfections were also confirmed by Cevik et al. (2020) and Root-Bernstein et al. (2021). Chen et al. (2020) repot that $5.1 \%$ of clinical isolates from 99 COVID-19 patients in Wuhan, China showed the presence of Klebsiella pneumoniae. At the same time, another study among COVID-19 patients in New York reported the infection with Klebsiella spp. having $10 \%$ prevalence with Klebsiella pneumoniae strains showing reduced sensitivity to major antibiotics like ciprofloxacin, cephalosporins and meropenem by $10 \%$ (Nori et al., 2021). The instigation by Li et al. (2020) on secondary bacterial infections in 102 COVID-19 patients shown presence of 159 strains with carbapenem-resistant Klebsiella pneumoniae. The study by Ukuhor et al. (2021) also lists AMR Klebsiella pneumoniae as one of the major isolates from the COVID19 inpatients. The prevalence of Klebsiella pneumoniae was further confirmed by Garcia-Vidal et al. (2020) as they were present in $14.2 \%$ of the isolates from COVID-19 patients at the time of their admission, in $25 \%$ of isolates as hospital acquired pneumonia agents and in another $25 \%$ of isolates from urinary tract infection agents. The study conducted by Karruli et al. (2020) in COVID-19 ICU patients at Monaldi Hospital, Naples, Italy during March and May 2020 declared carbapenem-resistant Klebsiella pneumoniae were the most common MDR bacterial pathogen isolated.

\subsection{Acinetobacter baumannii}

Acinetobacter baumannii is Gram negative, short, rod-shaped but round (coccobacillus) bacterium (Howard et al., 2012). Being an opportunistic pathogen, it affects human and became a very commonly encountered species in patients in intensive care units (ICUs), and are responsible for a number of health complications including urinary tract infections, meningitis, bacteremia, central venous catheter-related infections, ventilator associated pneumonia, wound infections, etc. (Michalopoulos and Falagas 2010; Howard et al., 2012). Acinetobacter baumannii was the largest single common species of bacteria with a prevalence of $35.8 \%$ when analyzed by Li et al. (2020) in Wuhan, China and surprisingly, $91.2 \%$ of them were carbapenem resistant. Carbapenem resistant Acinetobacter baumannii infections among COVID-19 patients were also reported by Perez et al. (2020) in the beginning of the pandemic itself in a New Jersey hospital. Rawson et al. (2020) and Chen et al. (2020) describe the incidents of secondary infections in COVID-19 patients with MDR Acinetobacter baumannii in different parts of the world including Wuhan, China. Mayoral et al. (2021) evaluated the coinfection by Acinetobacter baumannii in COVID-19 patients in a tertiary hospital in the community of Castilla and León, Spain. They reported that Acinetobacter baumannii caused the most of the MDR bacteremia and they concluded that, in ICU patients with COVID-19, the outbreak of this particular bacterium was the determining factor in the high rate of infection, morbidity and mortality. The coinfections by Acinetobacter baumanii in COVID19 ICUs were also explained by Duployez et al. (2020). An investigation conducted by Sharifipour et al. (2020) at a COVID-19 referral hospital in Iran found out that, $90 \%$ of the ICU patients were infected with Acinetobacter baumanii and from those patients, 17 strains of Acinetobacter baumanii were isolated of which all were resistant to all of the evaluated antibiotics. Fattorini et al. (2020) also listed Acinetobacter baumanii as one of the three most prevalent bacterial pathogens (with $91.7 \%$ carbapenem-resistance among them) causing coinfections in COVID-19 patients, and also notes that they form mixed infections often with Klebsiella pneumoniae. They also reported that, from the ICU-death group who were having bacterial coinfections, carbapenem resistant Acinetobacter baumannii was isolated. Karruli et al. (2020) also made a serious finding that, most of the MDR pathogens among the 23 isolates from COVID-19 patients in the ICU of Monaldi Hospital, Naples, Italy, most of them were Acinetobacter baumannii and carbapenem-resistant Klebsiella pneumoniae. The study by Patel et al. (2021) also underlines the above mentioned findings.

\subsection{Pseudomonas aeruginosa}

These facultative anaerobic bacteria are Gram negative bacilli which form a part of the normal gut flora (Iglewski,1996). They have already developed a number of MDR strains which would be resistant to at least three of five major antibiotics, viz., carbapenems, antipseudomonal penicillins, cephalosporins, aminoglycosides and fluoroquinolones, thereby causing prolonged morbidity and higher rate of mortality(Santajit and NitayaIndrawattan, 2016). Fu et al. (2020) analyzed that Pseudomonas aeruginosawas one of the causative agents responsible for MDR coinfection in five seriously 
ill COVID-19 patients. The retrospective study performed on 140 COVID-19 patients at a German University hospital showed the presence of Pseudomonas aeruginosa in $8.6 \%$ of the patients having bacterial coinfections (Rothe et al., 2021).

An investigation by Barrasa et al. (2020) in a Spanish ICU for COVID-19 patients reported that, those patients who had a longer stay in the ICU got secondary infection by Pseudomonas aeruginosa. During a study on COVID-19 patients in a Barcelona, Spain hospital. Garcia-Vidal et al. (2020) observedthat, the hospital acquired coinfections had Pseudomonas aeruginosa as one of the important pathogens. Zhang et al. (2020) also noted the Pseudomonas aeruginosa as a major agent causing coinfection in COVID-19 patients in Wuhan, China. Patel et al. (2021) described the presence of MDR Pseudomonas aeruginosa. According to Rawson et al. (2020), the secondary infections with MDR strains of pathogens like Pseudomonas aeruginosa may get easily infected when they receive therapies using invasive catheters. Many observations (including the those from Perez et al., 2020; Knight et al., 2021) are there which indicate that the hospital acquired infections like that of Pseudomonas aeruginosa is like a byproduct of this pandemic COVID-19. Different other studies also list Pseudomonas aeruginosa as one of the prime agents of COVID-19 bacterial coinfections. They include the studies conducted by Rusic et al. (2021) in New York, which reported $16 \%$ of the bacterial coinfections were caused by Pseudomonas aeruginosa and the investigation by Fattorini et al. (2020) which describes Pseudomonas aeruginosa as the main member causing coinfections in COVID-19 patients.

The study by Garcia-Vidal et al. (2020) at the Hospital Clinic of Barcelona (Spain), showed a notable presence of Pseudomonas aeruginosa as a bacterial coinfective agent in COVID-19 patients. Two COVID-19 patients who had bacterial coinfection in their lower respiratory tract showed the presence of Pseudomonas aeruginosa in them. Out of 11 patients showed hospital acquired infections, 3 of them were having Pseudomonas aeruginosa as one of the agents. Also, out of twelve, one of the urinary tract infections in COVID19 patients was also by Pseudomonas aeruginosa. Karruli et al. (2021) found out that all the three identified Pseudomonas aeruginosa isolates were carbapenem-resistant, which were isolated during a study on 32 patients at the COVID-19 ICU of the Monaldi Hospital, Naples, Italy. According to Knigh et al. (2021), patients who have been left with structural damages to the lungs after COVID-19 are at a high risk infection with MDR Pseudomonas aeruginosa due to possible continuous usage of antibiotics and hospitalizations.

\subsection{Enterobacter species and Escherichia coli}

Enterobacter spp. are Gram negative facultative anaerobic, motile enteric bacilli which are now generally called eneterobacterales that are significantly responsible for urinary and respiratory tract infections and bloodstream infections (McAdam et al., 2020; DavinRegli et al., 2019). Enterobacter spp. cause fatal nosocomial infections and display a broad multidrug resistance including to extended-spectrum cephalosporins (ESC), making them one of the major health concerns (Paterson, 2006; Mezzatesta et al., 2012; Davin-Regli and Pagès, 2015). Including in hospitalized people and immunocompromised patients, these bacteria, which have a wide range of antibiotic resistance mechanisms, cause opportunistic infections (Santajit and Nitaya Indrawattana, 2016).
Mahmoudi (2020) reported that, a study conducted on secondary infections in COVID-19 patients has found out the presence of Escherichia coli in 7 (16.28\%) of the samples and Enterobacter species in $5(11.63 \%)$ of the samples analyzed. Another study by Saber et al. (2021) in Bangladesh showed the presence of MDR Enterobacter spp. along with other coinfectors in a COVID-19 patient. The work of Garcia-Vidal et al. (2020) at a Spanish hospital, as described elsewhere in this article, also reported the presence of Escherichia coli as a major nosocomial infecting agent in COVID-19 patients. Lv et al. (2020), during their retrospective cohort analysis on 354 COVID-19 patients admitted to Wuhan University Renmin hospital found that, a critically ill patient was infected by Escherichia coli along with Candida sp. Zhang et al. (2020) also noted the coinfection of bacteria including Escherichia coli along with fungi in seriously ill COVID-19 patients in Wuhan, China. A research review study conducted Intra et al. (2020) at the COVID19 ICU of Desio Hospital, Lombardy, Italy, on 61 patients revealed the coinfection by Escherichia coli and Enterobacter sp. by 3\% each. The study conducted by Patel et al. (2021) at University of Maryland Medical Center, USA reported the presence of 44 Escherichiacoli isolates including $33 \mathrm{MDR}$ and 11 cefepime-resistant strains. According to Chen et al. (2020), patients receiving treatment using invasive catheters were more vulnerable to secondary infections with different MDR pathogens including with Escherichia coli. Rothe et al. (2020) found out that in the respiratory samples from 23 COVID-19 patients, one had the presence of Enterobacter sp. and six had Escherichia coli in them.

Rusic et al. (2021) in their study at a New York COVID-19 hospital reported that, $4 \%$ of the cases contained Escherichia coli. They also noted an increase by $42 \%$ in carbapenem resistant Entero bacteriaceae during in this pandemic season. Li et al. (2020) reports about an investigation in which 159 strains of bacteria causing coinfections in COVID-19 patients were isolated with $75 \%$ of the patients showing the presence of ESBL-producing Escherichia coli. The observational cohort analysis conducted by Garcia-Vidal et al. (2020) on 74 COVID-19 patients at the University Hospital Clinic of Barcelona, Spain, found Escherichia coli coinfection at various levels. $14.2 \%$ of the patients had coinfections with Escherichia coli at the time of admission itself. In $12.5 \%$ of them, Escherichia coli was present as a member of bacteraemia and in $33.5 \%$ of them, Escherichia coli was there as a urinary tract infecting agent. Contou et al. (2020) and Ghosh et al. (2021) also describes about the coinfections by Enterobacteriaceae.

\section{Conclusion}

The pandemic COVID-19, which have already infected more than 166 million people claiming more than 3.4 million lives worldwide continues its spree with no effective drugs developed so far. Rather than the viral infection itself, in most of the cases, they are the bacterial coinfections and secondary infections make the disease more dreaded by making the extended morbidity and higher mortality. When these infections are with MDR bacterial agents, the situation worsens. As analyzed in this review, the ESKAPE bacterial pathogens have a crucial role in making this disease a fatal one by their highly virulent and drug resistant strains. As we find in this retrospective investigation, the higher prevalence of each one of the ESKAPE member is concerning and it strongly demands the need for the development of potential, novel antibacterial agents. 


\section{Acknowledgements}

The author is grateful to the Deanship of Scientific Research, Prince Sattam bin Abdulaziz University, Al-Kharj, Saudi Arabia for its support and encouragement in conducting this review and publishing this report.

\section{Conflict of interest}

The author declares that there are no conflicts of interest relevant to this article.

\section{References}

Ansari, S; Hays, J; Kemp, A; Okechukwu, R; Murugaiyan, J; Ekwanzala, M.D. Alvarez, M.J.A.; Paul-Satyaseela, M.; Iwu, C.D.; Balleste-Delpierre, C.; Septimus, E.; Mugisha, L.; Fadare, J.; Chaudhuri, S.; Chibabhai, V.; Wadanamby, R.; Daoud, D.; Xiao, Y.; Parkunan, T.; Khalaf, Y.; M'Ikanatha, N. and van Dongen, M. (2021). Global AMR Insights Ambassador Network, The potential impact of the COVID-19 pandemic on global antimicrobial and biocide resistance: An AMR Insights global perspective, JAC-Antimicrobial Resistance, 3:2, June 2021, 1-12. https://doi.org/10.1093/jacamr/dlab038.

Ashurst, J.V. and Dawson, A. (2021) Klebsiella Pneumonia. (Updated 2021 Feb 5). Treasure Island (FL): Stat Pearls Publishing; from: https:/ /www.ncbi.nlm.nih.gov/books/NBK519004/.

Barrasa, H.; Martín, A.; Maynar, J.; Rello, J.; Fernández-Torres, M.; AguirreQuiñonero, A. and Canut-Blasco A. (2021). High rate of infections during ICU admission of patients with severe SARS-CoV-2 pneumonia: A matter of time? J. Infect., 82(5):186-230. https:// doi:10.1016/j.jinf.2020.12.001.

Cevik, M.; Bamford, C. and Ho, A. (2020). COVID-19 pandemic: A focused review for clinicians. Clinical microbiology and infection: The Official Publication of the European Society of Clinical Microbiology and Infectious Diseases, 26(7):842-847. https:// doi.org/10.1016/j.cmi.2020.04.023

Chen, N.; Zhou, M.; Dong, X.; Qu, J.; Gong, F.; Han, Y.; Qiu, Y.; Wang, J.; Liu, Y.; Wei, Y., Xia, J.; Yu, T.; Zhang, X. and Zhang, L. (2020). Epidemiological and clinical characteristics of 99 cases of 2019 novel coronavirus pneumonia in Wuhan, China: A descriptive study. Lancet, 395: 507-13.https://doi.org/10.1016/S0140-6736(20)30211-7

Chen, X.; Liao, B.; Cheng, L.; Peng, X.; Xu, X.; Li, Y.; Hu, T.; Li, J.; Zhou, X. and Ren, B. (2020). The microbial coinfection in COVID-19. Applied Microbiology and Biotechnology, 104(18):7777-7785. https:// doi.org/10.1007/s00253-020-10814-66

Cole, J and Barnard, E. (2021). The impact of the COVID-19 pandemic on healthcare acquired infections with multidrug resistant organisms. American Journal of Infection Control, 49:653-654. https:// doi.org/10.1016/j.ajic.2020.09.013

Contou, D.; Claudinon, A.; Pajot, O.; Micaëlo, M.; Flandre, P.L.; Dubert, M.; Cally, R.; Logre, E.; Fraissé, M.; Mentec, H. and Plantefève, G. (2020). Bacterial and viral co-infections in patients with severe SARS-CoV-2 pneumonia admitted to a French ICU. Ann. Intensive Care, 10(119) https://doi.org/10.1186/s13613-020-00736-x.

Davin-Regli, A. and Pagès, J.M. (2015). Enterobacteraerogenes and Enterobacter cloacae; versatile bacterial pathogens confronting antibiotic treatment. Front, Microbiol., 18:6-392. https://doi:10. 3389/fmicb.2015.00392.

Davin-Regli, A.; Lavigne, J.P. and Pagès, J.M. (2019). Update on Taxonomy, Clinical Aspects, and Emerging Antimicrobial Resistance. Clinical Microbiology Reviews., 32(4):2-19.https://doi:10.1128/CMR. 00002-19
Duployez, C.; Guern, L.R.; Tinez, C.; Lejeune, A.L.; Robriquet, L.; Six, S.; Loïez, C.; Wallet, F. and Panton-Valentine. (2020). Leukocidin-Secreting Staphylococcus aureus Pneumonia Complicating COVID-19. Emerg Infect Dis., 26(8):1939-1941. https://doi:10.3201/eid2608.201413

Fattorini, L.; Creti, R.; Palma, C. and Pantosti, A. (2020). Unit of antibiotic resistance and special pathogens of the department of infectious diseases, Istituto Superiore di Sanità, Rome. Bacterial coinfections in COVID-19: An underestimated adversary. Ann. Ist. Super. Sanita., 56(3):359-364. https://doi:10.4415/ANN_20_03_14.

Feldman, C. and Anderson, R. (2021). The role of co-infections and secondary infections in patients with COVID-19. Pneumonia, 13:5, 1-15. https://doi.org/10.1186/s41479-021-00083-w.

Fu, Y., Yang, Q.; Xu, M.; Kong, H.; Chen, H.; Fu, Y.; Yao, Y.; Zhou, H. and Zhou, J. (2020). Secondary Bacterial Infections in Critical Ill Patients With Coronavirus Disease 2019. Open Forum Infect. Dis., 7:220. https:/ /doi.org/10.1093/ofid/ofaa220

Garcia-Vidal, C.; Sanjuan. G. and Moreno-Garcia, E. (2020). Incidence of coinfections and superinfections in hospitalised patients with COVID19: A retrospective cohort study. Clin. Microbiol. Infect., https:/ /doi.org/10.1016/j.cmi.2020.07.041

Ghebreyesus, T.A. (2020). WHO Director-General's opening remarks at the media briefing on COVID-19. WHO. https://www.who.int/dg/ speeches/detail/who-director-general-s-opening-remarks-at-themedia-briefing-on-COVID-19-11-march-2020.

Ghosh, S.; Bornman, C. and Zafer, M.M. (2021). Antimicrobial Resistance Threats in the emerging COVID-19 pandemic: Where do we stand? J. Infect. Public Health, 14(5):555-560. https://doi.org/10.1093/ ofid/ofaa220 10.1016/j.jiph.2021.02.011

Howard, A.; O'Donoghue, M.; Feeney, A. and Sleator, R.D. (2012). Acinetobacter baumannii: An emerging opportunistic pathogen. Virulence, 3(3), 243-250. https://doi.org/10.4161/viru.19700.

Iglewski, B.H. (1996). Pseudomonas. Medical Microbiology. 4th edition. Galveston (TX): University of Texas Medical Branch at Galveston. Available from: https://www.ncbi.nlm.nih.gov/books/ NBK8326/

Intra, J.; Sarto, C.; Beck, E.; Tiberti, N.; Leoni, V. and Brambill, P. (2020). Bacterial and fungal colonization of the respiratory tract in COVID19 patients should not be neglected. American Journal of Infection Control, 48. 1130-1131. https://doi.org/10.1016/j.ajic.2020.06. 185

Karruli, A.; Boccia, F.; Gagliardi, M.; Patauner. F.; Ursi, M.P.; Sommese, P.; Rosa, R.; Murino, P.; Ruocco, G.; Corcione, A.; Andini, R.; Zampino, R. and DuranteMangoni, E. (2021). Multidrug-Resistant Infections and Outcome of Critically Ill Patients with Coronavirus Disease 2019: A Single Center Experience. Micro. Drug Resist., https://doi.org/10.1089/ mdr.2020.0489.

Knight, G.M.; Glover, R.E.; McQuaid, C.F.; Olaru, I.D.; Gallandat, K.; Leclerc, Q.J.; Fuller, N.M.; Willcocks, S.J.; Hasan, R.; van Kleef, E. and Chandler, C.I. (2021). Antimicrobial resistance and COVID-19: Intersections and Implications. Elife, 10:64139. https://doi.org/10.7554/eLife. 64139.

Lai, C.; Chen, S.; Ko, W. and Hsueh, P. (2021). Increased antimicrobial resistance during the COVID-19 pandemic. International Journal of Antimicrobial Agents, 57:106324 https://doi.org/10.1016/ j.ijantimicag.2021.106324.

Lai, C.C.; Wang, C.Y. and Hsueh, P.R (2020). Co-infections among patients with COVID-19: The need for combination therapy with non-antiSARS-CoV-2 agents? J. Microbiol. Immunol. Infect., 53:(4)505512. https://doi.org/10.1016/j.jmii.2020.05.013. 
Li, J.; Wang, J.; Yang, Y.; Cai, P.; Cao, J.; Cai, X and Zhang, Y. (2020). Etiology and antimicrobial resistance of secondary bacterial infections in patients hospitalized with COVID-19 in Wuhan, China: A retrospective analysis. Antimicrob. Resist. Infect. Control., 9:153. https://doi.org/10.1186/s13756-020-00819-11.

Lv, Z.; Cheng, S.;Huang, J.; Feng, L.; Zhang, B. and Li, Y. (2020). Clinical characteristics and co-infections of 354 hospitalized patients with COVID-19 in Wuhan, China: A retrospective cohort study. Microbes Infect., 22(4-5):195-9. https://doi.org/10.1016/j.micinf. 2020.05 .007

Mahmoudi, H. (2020). Bacterial co-infections and antibiotic resistance in patients with COVID-19. GMS Hyg. Infect. Control., 15. https:/ /doi.org/10.3205/dgkh000370.

Majumder, M.; Rahman, S.; Cohall, D.; Bharatha, A.; Singh, K.; Haque, M. and Gittens-St Hilaire, M. (2020). Antimicrobial Stewardship: Fighting Antimicrobial Resistance and Protecting Global Public Health. Infection and Drug Resistance, 13:4713-4738. https://doi.org/ 10.2147/IDR.S290835

Mazdeyasna, H.; Nori, P.; Patel, P.; Doll, M.; Godbout, E; Lee, K.; Noda, A.J.; Bearman, G. and Stevens, M.P. (2020). Antimicrobial Stewardship at the Core of COVID-19 Response Efforts: Implications for Sustaining and Building Programs. Curr. Infect. Dis. Rep., 22:923. https://doi.org/10.1007/s1 1908-020-00734-x.

McAdam, A.J. (2020). Enterobacteriaceae? Enterobacterales? What should we call enteric gram-negative bacilli? A Micro-Comic. Strip. Journal of Clinical Microbiology, 58:(2)e01888-19. https:/ /doi.org/10.1128/JCM.01888-19.

Mezzatesta, M.L.; Gona, F. and Stefani, S. (2012). Enterobacter cloacae complex: Clinical impact and emerging antibiotic resistance. Future Microbiol. 7(7):887-902. https://doi.org/10.2217/fmb.12.61.

Michalopoulos and Falagas M.E. (2010). Treatment of Acinetobacter infections. Expert Opin. Pharmacother., 11:(5)779-88. https:// doi.org/10.1517/14656561003596350.

Mirzaei, R.; Goodarzi, P.; Asadi, M.; Soltani, A.; Aljanabi, H.A.A.; Jeda, A.S.; Dashtbin, S.; Jalalifar, S.; Mohammadzadeh, R.; Teimoori, A.; Tari, K.; Salari, M.; Ghiasvand, S.; Kazemi, S.; Yousefimashouf, R.; Keyvani, H. and Karampoor, S. (2020). Bacterial co-infections with SARS-CoV-2. IUBMB Life, 72(10). 2097-2111.https://doi.org/10.1002/iub.2356.

Mulani, M.S.; Kamble, E.E.; Kumkar, S.N; Tawre, M.S. and Pardesi, K.R. (2019) Emerging strategies to combat ESKAPE pathogens in the era of antimicrobial resistance: A Review. Front. Microbiol., 10:539. https://doi.org/10.3389/fmicb.2019.00539.

Musthafa, M.; Gobianand, K. and Manohar, M. (2020). Anti-ESKAPE activity of green synthesized silver nanoparticles from Picrorhiza kurroa royle ex benth. Int. J. Pharm. Sci. and Res., 11:10. 5004-09. https://doi.org/10.13040/IJPSR.0975-8232.11(10).5004-09.

Navidinia, M. (2016). The clinical importance of emerging ESKAPE pathogens in nosocomial infections. Archives of Advances in Biosciences, 7(3):43-57. https://doi.org/10.22037/jps.v7i3.12584.

Nebreda-Mayoral, T.; Miguel-Gómez, M.A.; March-Rosselló, G.A.; PuenteFuertes, L.; Cantón-Benito, E., Martínez-García, A.M.; Muñoz-Martín, A.B. and Orduña-Domingo, A. (2020). Bacterial/fungal infection in hospitalized patients with COVID-19 in a tertiary hospital in the Community of Castilla y León, Spain. Enfermedades Infeccios as y Microbiologia Clinica., 23(33):1-8. https://doi.org/10.1016/ j.eimc.2020.11.003.

Nori, P.; Cowman, K.; Chen, V.; Bartash, R.; Szymczak, W.; Madaline, T.; Punjabi, K.C.; Jain, R.; Aldrich, M.; Weston, G.; Gialanella, P.; Corpuz, M.; Gendlina, I. and Guo, Y. (2021). Bacterial and fungal coinfections in COVID-19 patients hospitalized during the New York City pandemic surge. Infection Control and Hospital Epidemiology, 42(1)84-88. https:/ /doi.org/10.1017/ice.2020.368.
Patel, A.; Emerick, M.; Cabunoc, MK.; Williams, H.; Preas A.; Schrank, G.; Rabinowitz, R.; Luethy, P.; Johnson, K. and Leekha, S. (2021). Rapid Spread and control of multidrug-resistant gram-negative bacteria in COVID-19 Patient Care Units. Emerging Infectious Diseases, 27:4, 1234-1237. https://doi.org/10.3201/eid2704.204036

Paterson, D.L. (2006). Resistance in gram-negative bacteria: Enterobacteri aceae. Am. J. Infect. Control, 34:20-8. https://doi.org/10.1016/ j.ajic.2006.05.238.

Pelfrene, E.; Botgros, R. and Cavaleri, M. (2021). Antimicrobial multidrug resistance in the era of COVID-19: A forgotten plight? Antimicrob. Resist. Infect. Control, 10:21. https://doi.org/10.1186/s13756021-00893-z.

Pendleton, J.N.; Gorman, S.P. and Gilmore, B.F. (2013). Clinical relevance of the ESKAPE pathogens. Expert. Rev. Anti. Infect. Ther., 11(3):297308.https://doi.org/10.1586/eri.13.12.

Perez, S.; Innes, G.K.; Walters, M.S.; Mehr, J.; Arias, J.; Greeley, R. and Chew, D. (2020). Increase in hospital-acquired carbapenem-resistant Acinetobacterbaumannii Infection and Colonization in an Acute Care Hospital During a Surge in COVID-19 Admissions-New Jersey, February-July 2020. MMWR Morb. Mortal. Wkly. Rep., 69:18271831. http://dx.doi.org/10.15585/mmwr.mm6948e1

Prasetyoputri, A. Detection of Bacterial Coinfection in COVID-19 Patients Is a Missing Piece of the Puzzle in the COVID-19 Management in Indonesia. (2021).ACS Infect. Dis., 7(2)203-205. https://doi.org/10.1021/ acsinfecdis. 1 c00006.

Punjabi, C.D.; Madaline, T.; Gendlina, I.; Chen, V.; Nori, P. and Pirofski, L.A. (2020). Prevalence of methicillin-resistant Staphylococcus aureus (MRSA) in respiratory cultures and diagnostic performance of the MRSA nasal polymerase chain reaction (PCR) in patients hospitalized with coronavirus disease 2019 (COVID-19) pneumonia. Infect. Control Hosp. Epidemiol., 26:1-2. https://doi.org/10.1017/ ice. 2020.440 .

Ramsamy, Y.; Essack, S.Y.; Sartorius, B.; Patel, M. and Mlisana, K. P. (2018). Antibiotic resistance trends of ESKAPE pathogens in KwazuluNatal, South Africa: A five-year retrospective analysis. African Journal of Laboratory Medicine, 7(2):887. https://doi.org/ 10.4102/ajlm.v7i2.887

Rawson, T.; Wilson, R. and Holmes, A. (2021). Understanding the role of bacterial and fungal infection in COVID-19. Clinical Microbiology and Infection, 27:9-11. https://doi.org/10.1016/j.cmi.2020.07. 041 .

Rawson, T.M.; Moore, L.S.P.; Zhu, N.; Ranganathan, N.; Skolimowska, K.; Gilchrist, M.; Satta, G.; Cooke, G. and Holmes, A. (2020). Bacterial and fungal coinfection in individuals with coronavirus: A rapid review to support COVID-19 antimicrobial prescribing. Clin. Infect. Dis., 3(9):71. 2459-2468. https://doi.org/10.1093/cid/ciaa530.

Root-Bernstein R. (2021). Innate receptor activation patterns involving TLR and NLR synergisms in COVID-19, ALI/ARDS and sepsis cytokine storms: A review and model making novel predictions and therapeutic suggestions. Int. J. Mol. Sci., 22(4):2108. https:// doi.org/10.3390/ijms22042108.

Rossato, L.; Juliano, F. and Simionatto, S. (2020). Could the COVID-19 pandemic aggravate antimicrobial resistance? American Journal of Infection Control, 48:1127-1131 https://doi.org/10. 1016/ j.ajic.2020.06.192.

Rothe, K.; Feihl, S.; Schneider, j.; Wallnöfer, F.; Wurst, M.; Lukas, M.; Treiber, M.; Lahmer, T.; Heim,M.; Dommasch, M.; Waschulzik, B.; Zink, A.; Querbach, C.; Busch, D., Schmid, R.; Schneider, G. and Spinner, C. (2021). Rates of bacterial co-infections and antimicrobial use in COVID-19 patients: a retrospective cohort study in light of antibiotic stewardship. Eur J. Clin. Microbiol., Infect., Dis., 40:859-869. https://doi.org/ 10.1007/s $10096-020-04063-8$. 
Rusic, D.; Vilovic, M.; Bukic, J.; Leskur, D.; SeseljaPerisin, A.; Kumric, M.; Martinovic, D.; Petric, A.; Modun, D. and Bozic, J. (2021). Implications of COVID-19 pandemic on the emergence of antimicrobial resistance: Adjusting the response to future outbreaks. Life, 11:220. https:// doi.org/10.3390/life11030220.

Saber, S.; Ahmed, A.R.; Yasmin, N.; Alam, M.T.; Momen, A.B.I.; Hossain, M.M. and Alam, A.F. (2021). COVID-19 with multiple bacterial Co-infections: A case report. European Journal of Medical and Health Sciences, 3(1): 1-4. http://dx.doi.org/10.24018/ejmed.2021.3.1.646.

Said, M.S.; Tirthani, E. and Lesho E. Enterococcus Infections. (2021). In: Stat Pearls (Internet). Treasure island (FL): Stat Pearls Publishing; Available from: https://www.ncbi.nlm.nih.gov/books/NBK567759

Santajit, S. and Nitaya Indrawattana (2016). Mechanisms of antimicrobial resistance in ESKAPE pathogens, Biomed. Research International, 1:1-8. http://dx.doi.org/10.1155/2016/2475067.

Sharifipour, E.; Shams, S.; Esmkhani, M.; Khodadadi, J.; Fotouhi-Ardakani, R.; Koohpaei, A.; Doosti, Z. and Samad, E.J.G. (2020). Evaluation of bacterial co-infections of the respiratory tract in COVID-19 patients admitted to ICU. BMC Infect. Dis., 20:646. https://doi.org/10.1186/ s12879-020-05374-z.

Sola, I.; Almazán, F.; Zúñiga, S. and Enjuanes, L. (2015). Continuous and discontinuous RNA synthesis in coronaviruses. Annual review of Virology, 2(1):265-288. https://doi.org/10.1146/annurev-virology $-100114-055218$.

Taylor and Unakal, C.G. (2021). Staphylococcus aureus. In:StatPearls (Internet). Treasure island (FL): StatPearls Publishing; Available from: https://www.ncbi.nlm.nih.gov/books/NBK441868.

Ukuhor, H.O. (2021). The interrelationships between antimicrobial resistance, COVID-19, past, and future pandemics. J. Infect. Public Health, 14(1):53-60. https://doi.org/10.1016/j.jiph.2020.10.018
Vazzana, N.; Dipaola, F. and Ognibene, S. (2020). Procalcitonin and secondary bacterial infections in COVID-19: Association with disease severity and outcomes, Acta. Clinica. Belgica, 23:1-5. https://doi.org/ 10.1080/17843286.2020.1824749

WHO. Report, (2019). on Global Priority List of Antibiotic-Resistant Bacteria to Guide Research, Discovery, and Development of New Antibiotics. https://www.who.int/medicines/publications/globalpriority-list-antibiotic-resistantbacteria/en/

Wolfe, A.J.; Baunoch, D.; Wang, D.; Gnewuch, R.; Zhao, Z.; Halverson, T.; Cacdac, P.; Huang, S.; Lauterbach, T. and Luke, N. (2020). Co-occurrence of SARSCoV-2 and Respiratory Pathogens in the Frail Elderly. JOJ Urology and Nephrology, 7(3):555711. https://doi.org/10.19080/JOJUN. 2020.07 .555711$.

Yang, X.; Yu, Y.; Xu, J.; Shu, H.; Xia, J.; Liu, H.; Wu, Y.; Zhang, L.; Yu, Z; Fang, M.; Yu, T.; Wang, Y.; Pan, S.; Zou, X.; Yuan, X. and Shang, Y. (2020). Clinical course and outcomes of critically ill patients with SARS-CoV-2 pneumonia in Wuhan, China: A single-centered, retrospective, observational study. Lancet Respir. Med., 8:475-81. https://doi.org/ 10.1016/S2213-2600(20)30079-55

Zhang, G.; Hu, C.; Luo, L.; Fang, F.; Chen, Y.; Li, J.; Peng, Z. and Pan, H. (2020). Clinical features and short-term outcomes of 221 patients with COVID-19 in Wuhan. China J. Clin. Virol., 127:104-364. https:// doi.org/10.1016/j.jcv.2020.104364.

Zhu, N.; Zhang, D.; Wang, W.; Li, X.; Yang, B.; Song, J.; Zhao, X.; Huang, B.; Shi, W.; Lu, R.; Niu, P.; Zhan, F.; Ma, X.; Wang, D.; Xu, W.; Wu, G.; Gao, G.F. and Tan, W. (2020). China novel coronavirus investigating and research team. A novel coronavirus from patients with pneumonia in China, 2019. N Engl. J. Med., 382(8)727-733. https://doi.org/10.1056/ NEJMoa2001017. 